\title{
Efficacy of Secukinumab in the Treatment of Moderate to Severe Plaque Psoriasis in the North American Subgroup of Patients: Pooled Analysis of Four Phase 3 Studies
}

David Pariser · Ellen Frankel · Joel Schlessinger · Yves Poulin •

Ronald Vender · Richard G. Langley · Xiangyi Meng •

Adriana Guana · Judit Nyirady

Received: May 24, 2017 / Published online: December 7, 2017

(C) The Author(s) 2017. This article is an open access publication

\section{ABSTRACT}

Introduction: Demographic and disease characteristics may impact response to psoriasis therapies. The objective of this study is to explore the safety and efficacy profile of secukinumab in North American (NA) versus non-NA patients with moderate to severe psoriasis.

Methods: Data were pooled from four phase 3 studies of secukinumab. Secukinumab (300 and

Results were previously presented, in part, at: The American Academy of Dermatology; March 20-24, 2015; San Francisco, CA, USA.

Enhanced content To view enhanced content for this article, go to http://www.medengine.com/Redeem/ 36FCF06008EE2313.

Judit Nyirady is a former employee of Novartis Pharmaceuticals Corporation.

D. Pariser $(\bowtie)$

Eastern Virginia Medical School and Virginia

Clinical Research, Inc., Norfolk, VA, USA

e-mail: dpariser@pariserderm.com

E. Frankel

Clinical Partners, LLC, Johnston, RI, USA

J. Schlessinger

Advanced Skin Research Center, Omaha, NE, USA

Y. Poulin

Laval University and Centre Dermatologique du

Québec Métropolitain, Québec, QC, Canada
$150 \mathrm{mg}$ ) was administered at baseline, weeks 1 , 2 , and 3 , then every 4 weeks from week 4 to 48 . Results: Peak efficacy was observed at week 16 in NA and non-NA patients with secukinumab $300 \mathrm{mg}$ and secukinumab $150 \mathrm{mg}$, and disease clearance was maintained to week 52 . At week 52 with secukinumab $300 \mathrm{mg}$, Psoriasis Area and Severity Index (PASI) 90/100 response was achieved by $62.9 \% / 37.9 \%$ of NA patients, respectively, and $70.2 \% / 42.0 \%$ of non-NA patients, respectively. At week 52 with secukinumab $150 \mathrm{mg}$, PASI 90/100 response was achieved by $30.9 \% / 17.5 \%$ of NA patients, respectively, and $53.9 \% / 26.9 \%$ of non-NA patients, respectively. Response to secukinumab was rapid, and 50\% reduction in mean PASI was achieved in both groups after 2.9 weeks with secukinumab $300 \mathrm{mg}$ and 3.7 weeks with secukinumab $150 \mathrm{mg}$.

Conclusion: Despite differences in baseline characteristics, the efficacy and safety of secukinumab were similar among NA and non-NA patients.

\section{R. Vender}

Department of Medicine, McMaster University, and

Dermatrials Research Inc., Hamilton, ON, Canada

R. G. Langley

Dalhousie University, Halifax, NS, Canada

X. Meng · A. Guana · J. Nyirady

Novartis Pharmaceuticals Corporation, East

Hanover, NJ, USA 
Funding: Novartis Pharma AG.

Plain Language Summary: Plain language summary available for this article.

Keywords: Clear or almost clear skin; Clinical trial; North America; Patient-reported outcomes; Pooled; Psoriasis; Quality of life; Secukinumab

\section{PLAIN LANGUAGE SUMMARY}

Inflammation causes psoriasis on the skin. Secukinumab is a drug that reduces inflammation. We studied how well secukinumab cleared psoriasis in 393 patients from North America and 990 patients not from North America. We also recorded whether side effects occurred with secukinumab. Secukinumab was given by injection for 5 weeks, then monthly for 1 year. After 12 weeks of secukinumab, $76.0 \%$ of patients from North America had skin that was clear or almost clear of psoriasis, $41.2 \%$ of patients from North America had skin that was clear of psoriasis, $66.2 \%$ of patients not from North America had skin that was clear or almost clear of psoriasis, and $28.1 \%$ of patients not from North America had skin that was clear of psoriasis. In both groups, skin remained clear from 12 weeks to 1 year of treatment. After 1 year of secukinumab, $67.7 \%$ of patients from North America had skin that was clear or almost clear of psoriasis, $39.8 \%$ of patients from North America had skin that was clear of psoriasis, $73.1 \%$ of patients not from North America had skin that was clear or almost clear of psoriasis, and $41.4 \%$ of patients not from North America had skin that was clear of psoriasis. Secukinumab also reduced discomfort from itching and pain. The most common side effects were common cold, upper respiratory infection, headache, diarrhea, and cough. Secukinumab completely or almost completely cleared the skin of many patients with psoriasis. Where they lived in the world did not affect skin clearance.

\section{INTRODUCTION}

Differences in demographic and disease characteristics between patients with psoriasis from different geographic regions and ethnic backgrounds have been suggested to impact the efficacy and safety of therapies [1-6]. For example, the typically lighter body weights of patients from Asia may impact response to treatment [7]. In addition, physicians should be aware that differences in the rates of comorbidities between patient groups could affect treatment decisions and outcomes. These differences could be of practical significance for clinicians and patients but may be obscured by the way in which data are reported in pivotal, often global, randomized, controlled, clinical trials, which do not delineate findings in this manner.

In 2013, the prevalence of psoriasis was estimated to be 7.4 million people in the USA [8]. Due to its chronic nature, psoriasis requires long-term management that incurs substantial costs. The estimated total annual cost of psoriasis was US $\$ 112$ billion in the USA in 2013 [9] and CAN $\$ 1.7$ billion in Canada in 2008 [10]. Furthermore, US patients with psoriasis are estimated to experience almost US $\$ 2000$ in reduced productivity per year and a further US $\$ 2200$ reduction in health-related quality of life compared with controls [11].

Despite the substantial physical and emotional burdens associated with psoriasis [12], many patients in the USA do not receive adequate treatment to control disease symptoms. Surveys conducted by the National Psoriasis Foundation in 2011 found that 23.6\% of patients with moderate psoriasis and $9.4 \%$ of patients with severe psoriasis in the USA were not receiving treatment [13]. In addition, 52.3\% of patients with psoriasis reported being dissatisfied with their treatment. The importance of clear skin cannot be overlooked because clinically important differences in quality of life are reported by people with clear skin compared with those with almost clear skin [14].

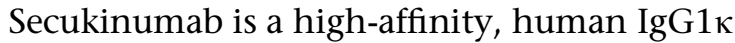
monoclonal antibody that selectively binds to and neutralizes interleukin-17A. In phase 3 trials in psoriasis, secukinumab has been demonstrated to result in significantly greater skin clearance compared with placebo, etanercept, and ustekinumab, with a comparable safety profile [15-18]. In this post hoc analysis, data were pooled from four phase 3 trials to evaluate 
the safety and efficacy profile of secukinumab in North American (NA) and non-NA patients.

\section{METHODS}

Data from 393 NA (USA and Canada) and 990 non-NA patients (Argentina, Australia, Belgium, Colombia, Egypt, Estonia, Finland, France, Germany, Guatemala, Hungary, Iceland, India, Israel, Italy, Japan, South Korea, Latvia, Lithuania, Mexico, The Philippines, Poland, Romania, Singapore, Spain, Sweden, Taiwan, and UK) with moderate to severe psoriasis were pooled from four phase 3, randomized, double-blind studies of secukinumab (Fig. 1). The included studies were ERASURE, FIXTURE, FEATURE, and JUNCTURE [15-17]. The article does not contain any new studies with human or animal subjects performed by any of the authors.

All studies had the following inclusion criteria: adults 18 years or older with chronic plaque-
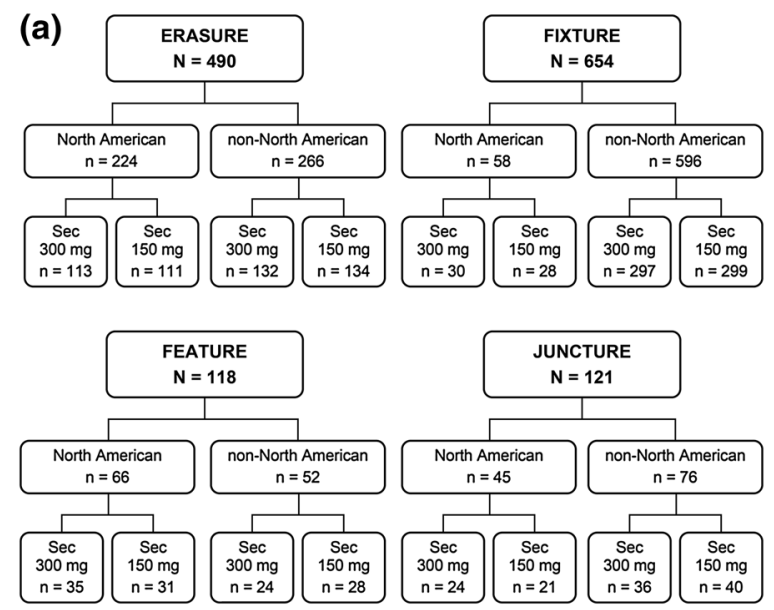

(b)

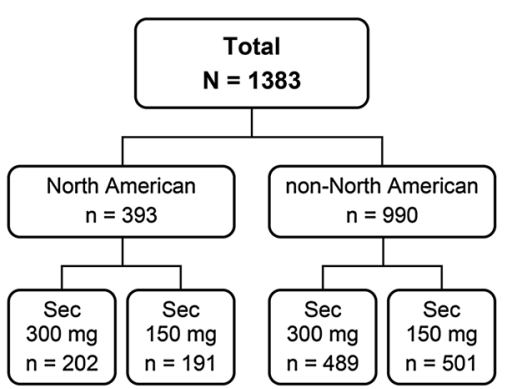

Fig. 1 Composition of pooled study population by a phase 3 trial and $\mathbf{b}$ region. $S e c$ secukinumab type psoriasis considered inadequately controlled by topical treatment, phototherapy, and/ or previous systemic therapy, and who were diagnosed at least 6 months before randomization; baseline Psoriasis Area and Severity Index (PASI) score $\geq 12$, Investigator's Global Assessment (IGA) modified 2011 score $\geq 3$, and total affected body surface area (BSA) $\geq 10 \%$. Exclusion criteria included active ongoing inflammatory diseases; active, ongoing, chronic, or recurrent infectious disease, or evidence of tuberculosis infection; or an underlying condition significantly immunocompromising the patient and/ or placing the patient at unacceptable risk for receiving immunomodulatory therapy [e.g., lymphoproliferative disease; malignancy; history of malignancy within the past 5 years; medical history of human immunodeficiency virus, hepatitis $\mathrm{B}$, or hepatitis $\mathrm{C}]$.

\section{Study Designs and Assessments}

All patients received secukinumab (300 or $150 \mathrm{mg}$ ) at baseline, weeks 1,2 and 3 , then every 4 weeks from week 4 to 48 . In all studies, the coprimary endpoints were $75 \%$ improvement from baseline in PASI score (PASI 75) and IGA modified 2011 (IGA mod 2011) [19] response of $0 / 1$ (clear/almost clear) at week 12 . Secondary endpoints included PASI 90 and PASI 100 response rates at week 12. Achievement of Dermatology Life Quality Index (DLQI) [20] score of $0 / 1$, representing little or no effect of psoriasis on patient quality of life, was also measured at week 12. In ERASURE and FIXTURE, reduction in symptoms of itching, pain, and scaling as measured by Psoriasis Symptom Diary $\odot$ (PSD) [21] at week 12 were key secondary endpoints.

\section{Pooled Analysis Design and Statistical Methods}

Data up to week 52 of the ERASURE, FIXTURE, FEATURE, and JUNCTURE studies were pooled. Missing values were handled by the multiple imputation method in which missing data are replaced by values derived from large datasets of possible values. The SAS multiple imputation 
procedure was used to generate datasets for 500 imputations. For comparison of response to secukinumab treatment between NA and nonNA population, the Cochran-Mantel-Haenszel test was used and adjusted for age $(<45$ or $\geq 45$ years), gender, study site, body weight, treatment group, previous systemic treatment (including oral and biologic), previous biologic treatment, and baseline PASI score $(\leq 20$ or $>20$ ). Sensitivity analysis of the contribution of patient factors to efficacy was performed by logistic regression with study site, weight $(<90$ or $\geq 90 \mathrm{~kg}$ ), age, gender, body mass index (BMI), baseline PASI score, race (Caucasian or nonCaucasian), current smoking status, and treatment as explanatory variables. Factors predictive of secukinumab efficacy in the overall patient population were determined by first performing separate regression analyses including one of the following: current smoking status, race (Caucasian or non-Caucasian), gender, baseline BMI, and age in addition to NA and treatment as regressors. Multiple regression analysis was then performed for factors with $P<0.05$ from the earlier analysis, all included together with study site, NA, and treatment as additional explanatory variables. All analyses were not prespecified and no adjustments were made for multiple comparisons. Safety data are presented for all patients who took at least one dose of study drug during the treatment period.

\section{RESULTS}

\section{Patients}

Differences were observed in demographic and baseline characteristics between the NA and non-NA populations (Table 1). Notably, the secukinumab 300 and $150 \mathrm{mg}$ NA populations, compared with the non-NA populations, had greater mean body weight (96.3-97.4 versus $82.5 \mathrm{~kg} ; P<0.001)$ and BMI $(32.6-32.8$ versus $\left.28.1 \mathrm{~kg} / \mathrm{m}^{2} ; P<0.001\right)$. In the NA population, compared with the non-NA population, there were more White patients $(83.2-83.8 \%$ versus 67.7-68.9\%) and fewer Asian patients (5.8-7.4\% versus 23.3-23.6\%). The NA populations had a lower mean baseline PASI score (19.4-20.2 versus 23.8-24.0; $P<0.001)$ and less BSA affected $(25.2-26.6 \%$ versus $35.9-36.3 \%$; $P<0.001)$. Psoriatic arthritis was more common in the NA population $(23.0-24.3 \%)$ than in the non-NA population $(15.2-16.6 \% ; P<0.001)$. Differences were also observed in exposure rates to previous therapies for psoriasis between the NA and nonNA population: a lower proportion of NA patients was previously exposed to nonbiologic systemic psoriasis therapy $(37.6-45.0 \%$ versus $60.7-61.3 \% ; P<0.001)$ and, similarly, fewer NA patients had previously failed a systemic psoriasis therapy $(37.6-46.1 \%$ versus $50.9 \%$; $P<0.001)$. However, significantly more NA patients than non-NA patients had been previously exposed to a biologic psoriasis therapy (45.5-52.9\% versus $11.0-12.0 \% ; P<0.001)$.

\section{Efficacy}

IGA mod 2011 and PASI responses peaked at week 16 and were sustained to week 52 in both NA and non-NA patients with both secukinumab $300 \mathrm{mg}$ and secukinumab $150 \mathrm{mg}$ (Figs. 2, 3, 4, 5, 6). At week 16, the greatest efficacy was observed with secukinumab $300 \mathrm{mg}$; PASI 90 and PASI 100 responses were achieved by $75.6 \%$ and $47.2 \%$ of NA patients, respectively. In comparison, PASI 90 and PASI 100 responses were achieved by $75.1 \%$ and $40.1 \%$ of non-NA patients, respectively. At week 16 with secukinumab $150 \mathrm{mg}$, PASI 90 and PASI 100 responses were achieved by $42.5 \%$ and $21.1 \%$ of NA patients, respectively, and by $62.1 \%$ and $26.5 \%$ of non-NA patients, respectively. Efficacy responses at week 12 and 52 are presented in Table 2.

Differences in efficacy between NA and nonNA patients were more pronounced with secukinumab $150 \mathrm{mg}$ than with secukinumab $300 \mathrm{mg}$. For example, comparison of the difference in PASI 90 response rates at week 52 showed a greater difference between NA and non-NA patients with secukinumab $150 \mathrm{mg}$ than with secukinumab $300 \mathrm{mg}$. From week 12 onward, non-NA patients consistently reported having greater skin clearance with secukinumab $150 \mathrm{mg}$ than NA patients. Less variation was observed in efficacy responses between NA and 
Table 1 Patient demographics and baseline disease characteristics

\begin{tabular}{|c|c|c|c|c|c|}
\hline \multirow[t]{2}{*}{ Parameter } & \multicolumn{2}{|c|}{ North American subgroup } & \multicolumn{2}{|c|}{ Non-North American subgroup } & \multirow{2}{*}{$\begin{array}{l}P \text { value } \\
\text { NA versus } \\
\text { non-NA }\end{array}$} \\
\hline & $\begin{array}{l}\text { Secukinumab } \\
300 \mathrm{mg} \\
(n=202)\end{array}$ & $\begin{array}{l}\text { Secukinumab } \\
150 \mathrm{mg} \\
(n=191)\end{array}$ & $\begin{array}{l}\text { Secukinumab } \\
300 \mathrm{mg} \\
(n=489)\end{array}$ & $\begin{array}{l}\text { Secukinumab } \\
150 \mathrm{mg} \\
(n=501)\end{array}$ & \\
\hline Sex (male), $n(\%)$ & $137(67.8)$ & $131(68.6)$ & $340(69.5)$ & $354(70.7)$ & $0.487^{*}$ \\
\hline Age (years), mean (SD) & $46.2(13.8)$ & $45.7(14.0)$ & $44.3(13.1)$ & $44.9(13.2)$ & $0.107^{\dagger}$ \\
\hline Range & $19-83$ & $18-83$ & $18-79$ & $18-79$ & \\
\hline Race, $n(\%)$ & & & & & $<0.001^{*}$ \\
\hline White & $168(83.2)$ & $160(83.8)$ & $337(68.9)$ & $339(67.7)$ & \\
\hline Asian & $15(7.4)$ & $11(5.8)$ & $114(23.3)$ & $118(23.6)$ & \\
\hline Black & $9(4.5)$ & $12(6.3)$ & 0 & $1(0.2)$ & \\
\hline Other or unknown & $10(5.0)$ & $8(4.2)$ & $38(7.8)$ & $43(8.6)$ & \\
\hline Body weight $(\mathrm{kg})$, mean (SD) & $96.3(27.4)$ & $97.4(27.3)$ & $82.5(19.9)$ & $82.5(19.9)$ & $<0.001^{\dagger}$ \\
\hline Range & $48-219$ & $49-215$ & $45-186$ & $43-163$ & \\
\hline BMI $\left(\mathrm{kg} / \mathrm{m}^{2}\right)$, mean $(\mathrm{SD})$ & $32.6(8.4)$ & $32.8(9.0)$ & $28.1(5.6)$ & $28.1(5.6)$ & $<0.001^{\dagger}$ \\
\hline Range & $18-67$ & $19-80$ & $17-53$ & $17-50$ & \\
\hline PASI score, mean (SD) & $19.4(7.4)$ & $20.2(9.2)$ & $24.0(9.8)$ & $23.8(10.1)$ & $<0.001^{\dagger}$ \\
\hline Range & $12-50$ & $12-58$ & $11-72$ & $12-70$ & \\
\hline Total BSA, mean (SD) & $25.2(14.9)$ & $26.6(17.0)$ & $36.3(19.2)$ & $35.9(19.0)$ & $<0.001^{\dagger}$ \\
\hline Range & $10-79$ & $10-91$ & $10-100$ & $10-92$ & \\
\hline IGA modified 2011 score, $n(\%)$ & & & & & $0.652^{*}$ \\
\hline 3 (moderate disease) & $129(63.9)$ & $116(60.7)$ & $307(62.8)$ & $323(64.5)$ & \\
\hline 4 (severe disease) & $73(36.1)$ & $75(39.3)$ & $182(37.2)$ & $178(35.5)$ & \\
\hline $\begin{array}{l}\text { Time since first psoriasis } \\
\text { diagnosis (years), mean (SD) }\end{array}$ & $18.3(12.4)$ & $19.4(13.0)$ & $16.5(11.8)$ & $17.4(12.2)$ & $0.01^{\dagger}$ \\
\hline Range & $0.6-57.5$ & $0.6-61.4$ & $0.5-61.5$ & $0.5-69.0$ & \\
\hline Psoriatic arthritis, $n(\%)$ & $49(24.3)$ & $44(23.0)$ & $81(16.6)$ & $76(15.2)$ & $<0.001^{*}$ \\
\hline \multicolumn{6}{|c|}{ Previous exposure to any systemic psoriasis therapy, including biologics } \\
\hline Yes, $n(\%)$ & $129(63.9)$ & $126(66.0)$ & $309(63.2)$ & $321(64.1)$ & $0.679^{*}$ \\
\hline \multicolumn{6}{|c|}{ Previous failure of any systemic psoriasis therapy, including biologics } \\
\hline Yes, $n(\%)$ & $76(37.6)$ & $88(46.1)$ & $249(50.9)$ & $255(50.9)$ & $<0.001^{*}$ \\
\hline \multicolumn{6}{|c|}{ Previous exposure to biologic systemic psoriasis therapy } \\
\hline Yes, $n(\%)$ & $92(45.5)$ & $101(52.9)$ & $54(11.0)$ & $60(12.0)$ & $<0.001^{*}$ \\
\hline
\end{tabular}


Table 1 continued

\begin{tabular}{|c|c|c|c|c|c|}
\hline \multirow[t]{2}{*}{ Parameter } & \multicolumn{2}{|c|}{ North American subgroup } & \multicolumn{2}{|c|}{ Non-North American subgroup } & \multirow{2}{*}{$\begin{array}{l}P \text { value } \\
\text { NA versus } \\
\text { non-NA }\end{array}$} \\
\hline & $\begin{array}{l}\text { Secukinumab } \\
300 \mathrm{mg} \\
(n=202)\end{array}$ & $\begin{array}{l}\text { Secukinumab } \\
150 \mathrm{mg} \\
(n=191)\end{array}$ & $\begin{array}{l}\text { Secukinumab } \\
300 \mathrm{mg} \\
(n=489)\end{array}$ & $\begin{array}{l}\text { Secukinumab } \\
150 \mathrm{mg} \\
(n=501)\end{array}$ & \\
\hline \multicolumn{6}{|c|}{ Previous failure of biologic systemic psoriasis therapy } \\
\hline Yes, $n(\%)$ & $30(14.9)$ & $44(23.0)$ & $20(4.1)$ & $25(5.0)$ & $0.844^{*}$ \\
\hline \multicolumn{6}{|c|}{ Previous exposure to nonbiologic systemic psoriasis therapy } \\
\hline Yes, $n(\%)$ & $76(37.6)$ & $86(45.0)$ & $297(60.7)$ & $307(61.3)$ & $<0.001^{*}$ \\
\hline
\end{tabular}

$P$ values are for comparison of pooled NA and non-NA patient groups

$B M I$ body mass index, $B S A$ body surface area, IGA Investigator's Global Assessment, NA North American, PASI Psoriasis Area and Severity Index, $S D$ standard deviation

${ }^{*} P$ value determined by chi-square test or Fisher's exact test (excluding missing values)

${ }^{\dagger} P$ values determined by two-sample $t$ test

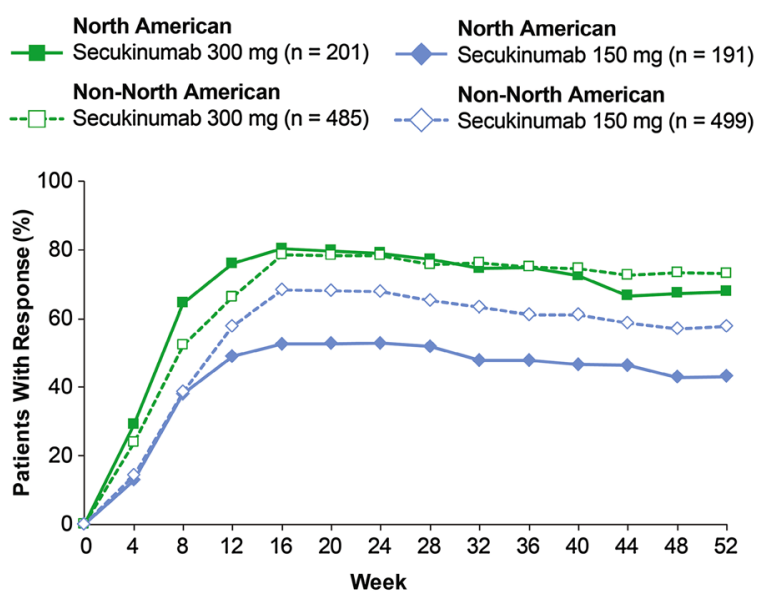

Fig. 2 Modified IGA responses of 0 or $1 . n$ represents the number of evaluable subjects. Missing values were handled by multiple imputation. IGA mod 2011 Investigator's Global Assessment, 2011 modified version

non-NA patients with secukinumab $300 \mathrm{mg}$. At week 12, a trend toward better response in NA patients compared with non-NA patients was observed when adjusted for age $(<45$ or $\geq 45$ years), gender, study site, body weight, treatment group, previous systemic treatment (including oral and biologic), previous biologic treatment, and baseline PASI score $(\leq 20$ or

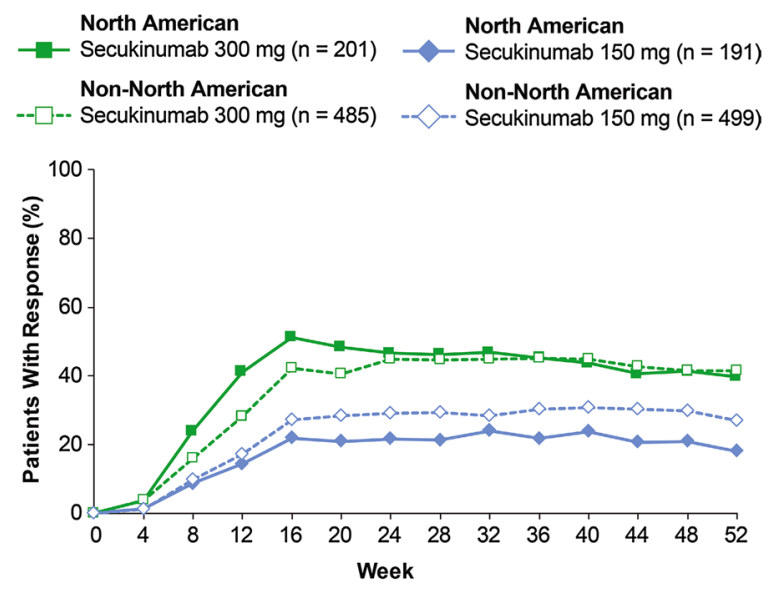

Fig. 3 Modified IGA responses of $0 . n$ represents the number of evaluable subjects. Missing values were handled by multiple imputation. IGA $\bmod 2011$ Investigator's Global Assessment, 2011 modified version

>20) (Table 3). Sensitivity analysis of the contribution of individual patient factors to efficacy at week 12 found BMI as the only factor with a consistently significant effect on efficacy across different efficacy measures in both NA and nonNA patients (Table 4). Separate regression analyses with each factor were performed to identify patient factors associated with secukinumab 


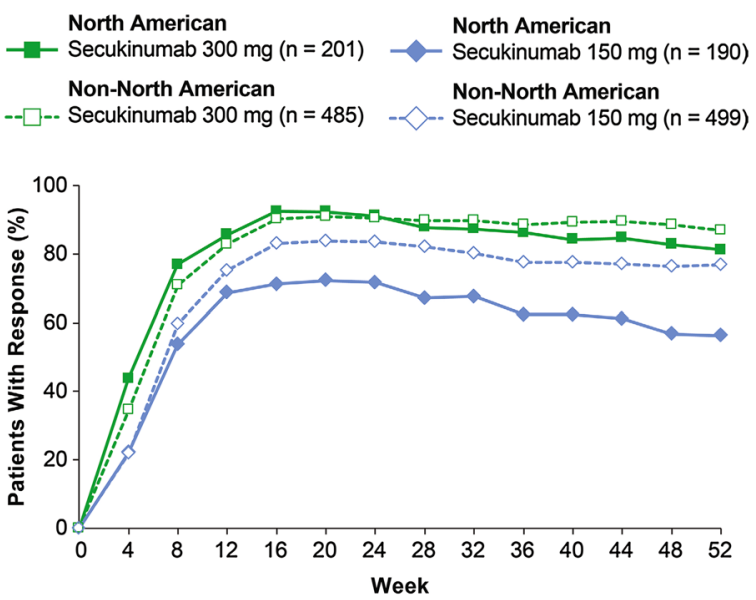

Fig. 4 PASI 75 responses. $n$ represents the number of evaluable subjects. Missing values were handled by multiple imputation. PASI $7575 \%$ improvement from baseline Psoriasis Area and Severity Index

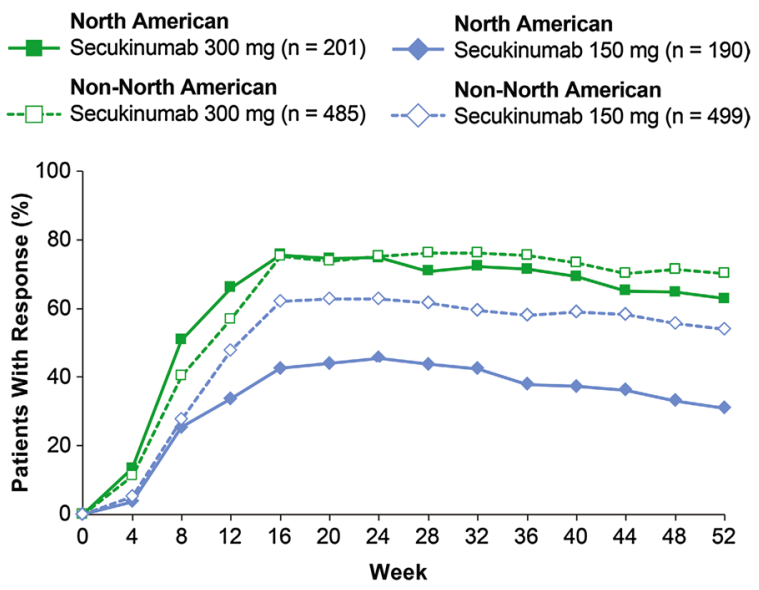

Fig. 5 PASI 90 responses. $n$ represents the number of evaluable subjects. Missing values were handled by multiple imputation. PASI 90 90\% improvement from baseline Psoriasis Area and Severity Index

response at week 12 in the overall patient population. Patients factors identified as significant $(P<0.05)$ from these analyses were then subjected to multiple regression analysis to evaluate their ability to predict secukinumab response (Table 5). Across the different efficacy variables, BMI was the only factor found to be a consistently significant predictor of response to secukinumab. Interestingly, NA patients were significantly more likely to achieve complete psoriasis clearance as measured by IGA mod

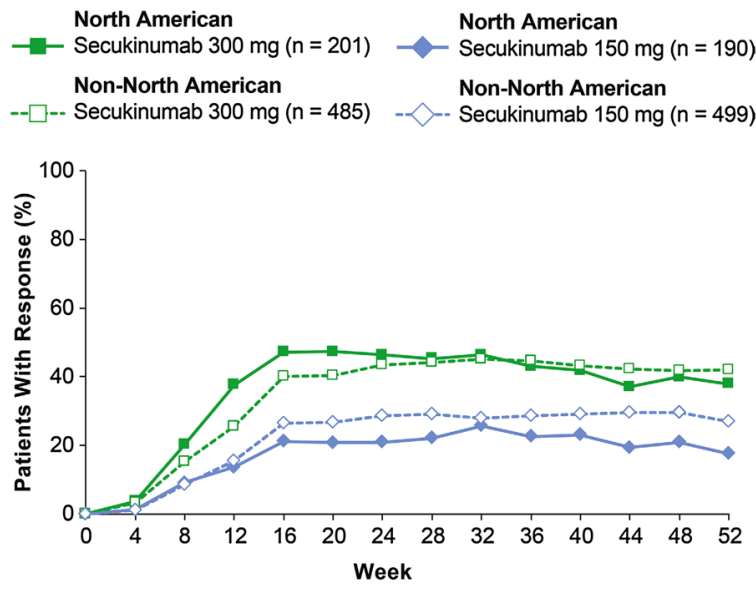

Fig. 6 PASI 100 responses. $n$ represents the number of evaluable subjects. Missing values were handled by multiple imputation. PASI 100 100\% improvement from baseline Psoriasis Area and Severity Index

20110 response [odds ratio (95\% confidence interval), $1.84(1.32-2.56) ; P=0.0003]$ and PASI 100 response [odds ratio (95\% confidence interval), 1.91 (1.33-2.73); $P=0.0004]$.

The speed of response to secukinumab was rapid in both NA and non-NA patients, and the time to $50 \%$ reduction in mean PASI score was similar in both populations (Fig. 7). With secukinumab $300 \mathrm{mg}, 50 \%$ reduction in mean PASI score was achieved in 2.9 weeks for both NA patients $[95 \%$ confidence interval (CI) 2.7-3.1 weeks] and non-NA patients (95\% CI 2.8-3.1 weeks). With secukinumab $150 \mathrm{mg}$, $50 \%$ reduction in mean PASI score was achieved in 3.7 weeks for both NA patients $(95 \%$ CI $3.4-4.2$ weeks) and non-NA patients (95\% CI 3.5-3.9 weeks).

Secukinumab was also observed to improve patient quality of life in both NA and non-NA patients. At week 12, DLQI responses of $0 / 1$ were similar between NA patients $(60.7 \%$ with secukinumab $300 \mathrm{mg}$ and $45.5 \%$ with secukinumab $150 \mathrm{mg}$ ) and non-NA patients $(58.8 \%$ with secukinumab $300 \mathrm{mg}$ and $51.8 \%$ with secukinumab $150 \mathrm{mg}$; Table 6). These responses were maintained to week 52 in both NA patients $(64.6 \%$ with secukinumab $300 \mathrm{mg}$ and $44.2 \%$ with secukinumab $150 \mathrm{mg}$ ) and non-NA patients $(69.2 \%$ with secukinumab $300 \mathrm{mg}$ and $57.3 \%$ with secukinumab 
Table 2 Efficacy responses at week 12 and week 52

\begin{tabular}{|c|c|c|c|c|}
\hline \multirow{2}{*}{$\begin{array}{l}\text { Endpoint, patients, \% achieving } \\
\text { response }\end{array}$} & \multicolumn{2}{|c|}{ North American subgroup } & \multicolumn{2}{|c|}{ Non-North American subgroup } \\
\hline & $\begin{array}{l}\text { Secukinumab } \\
300 \mathrm{mg}\end{array}$ & $\begin{array}{l}\text { Secukinumab } \\
150 \mathrm{mg}\end{array}$ & $\begin{array}{l}\text { Secukinumab } \\
300 \mathrm{mg}\end{array}$ & $\begin{array}{l}\text { Secukinumab } \\
150 \mathrm{mg}\end{array}$ \\
\hline \multicolumn{5}{|l|}{ Week 12} \\
\hline IGA $0 / 1$ & 76.0 & 49.0 & 66.2 & 57.7 \\
\hline IGA 0 & 41.2 & 14.3 & 28.1 & 17.2 \\
\hline PASI 75 & 85.7 & 68.7 & 82.9 & 75.3 \\
\hline PASI 90 & 66.1 & 33.7 & 56.9 & 47.6 \\
\hline PASI 100 & 37.6 & 13.6 & 25.5 & 15.5 \\
\hline \multicolumn{5}{|l|}{ Week 52} \\
\hline IGA $0 / 1$ & 67.7 & 43.1 & 73.1 & 57.7 \\
\hline IGA 0 & 39.8 & 18.0 & 41.4 & 27.0 \\
\hline PASI 75 & 81.2 & 56.3 & 86.9 & 77.0 \\
\hline PASI 90 & 62.9 & 30.9 & 70.2 & 53.9 \\
\hline PASI 100 & 37.9 & 17.5 & 42.0 & 26.9 \\
\hline
\end{tabular}

Number of evaluable patients in NA population: secukinumab $300 \mathrm{mg}(n=201$ for both IGA and PASI), secukinumab $150 \mathrm{mg}(n=191$ for IGA and $n=190$ for PASI)

Number of evaluable patients in non-NA population: secukinumab $300 \mathrm{mg}(n=485$ for both IGA and PASI), secukinumab $150 \mathrm{mg}(n=499$ for IGA and PASI)

IGA $(\bmod 2011) 0 / 1$ Investigator's Global Assessment, $2011 \operatorname{modified~version,~improvement~to~scores~of~} 0$ or 1 (clear or almost clear skin), NA North American, PASI 75/90/100 Psoriasis Area and Severity Index 75\%/90\%/100\% improvement from baseline in Psoriasis Area and Severity Index

$150 \mathrm{mg}$ ). Improvement in patient-reported symptoms of itching, pain, and scaling was observed after 12 weeks of treatment with secukinumab in both NA and non-NA patients (Fig. 8). A similar proportion of NA and nonNA patients showed improvement in these symptoms with secukinumab $150 \mathrm{mg}$, and, interestingly, there was a trend for greater response with secukinumab $300 \mathrm{mg}$ in NA patients than in non-NA patients, especially for pain and scaling.

\section{Safety}

Secukinumab demonstrated a good and comparable safety profile in both the NA and nonNA populations (Table 7). Overall rates of adverse events (AEs) and serious AEs were similar between the two populations. Nasopharyngitis was the most common $\mathrm{AE}$ and occurred at a numerically greater rate in the non-NA population (33.1-35.5 events per 100 patient-years) than in the NA population (22.7-24.3 events per 100 patient-years). Upper respiratory tract infection was the second most common AE in the NA population and occurred at a numerically greater rate than in the non-NA population (15.9-23.9 versus 5.8-6.2 events per 100 patient-years). No serious Candida infections were reported in either population, and all cases of candidiasis resolved on their own or with standard treatment and did not lead to discontinuation of secukinumab. Rates of discontinuation due to AEs were similar between the NA (4.5-5.2\%) and non-NA (2.5-3.0\%) populations. 
Table 3 Effect of geographical region on efficacy at week 12 for NA versus non-NA patients

\begin{tabular}{ll}
\hline Response criterion & Odds ratio $(\mathbf{9 5 \% ~ C I )}$ \\
\hline IGA 0/1 & $1.28(0.86-1.90)$ \\
IGA 0 & $1.77(1.14-2.72)$ \\
PASI 75 & $1.10(0.67-1.82)$ \\
PASI 90 & $1.14(0.77-1.68)$ \\
PASI 100 & $1.61(1.02-2.54)$ \\
\hline
\end{tabular}

$C I$ confidence interval, $I G A$ Investigator's Global Assessment, NA North American, PASI Psoriasis Area and Severity Index

The odds ratio represents the comparison of response to secukinumab treatment between NA and non-NA patients using the Cochran-Mantel-Haenszel test adjusted for age $(<45$ or $\geq 45$ years), gender, study site, body weight, treatment group, previous systemic treatment (including oral and biologic), previous biologic treatment, and baseline PASI score $(\leq 20$ or $>20)$

\section{DISCUSSION}

Secukinumab demonstrated fast, robust, and sustained disease clearance with a good and comparable safety profile for both NA and nonNA patients with moderate to severe psoriasis. The efficacy profiles of secukinumab to week 52 in NA and non-NA patients remained similar to previous results from the overall populations $[15,22]$. Furthermore, the efficacy of secukinumab between NA and non-NA patients was similar despite differences in baseline characteristics between the two populations. For example, patients from NA were heavier, had greater BMI, and were more likely to have psoriatic arthritis. Patients from NA were also more likely to have been previously exposed to biologic therapy, but no significant differences in the rates of biologic failure were reported between the groups. Differences were also observed in the racial composition of the two

Table 4 Sensitivity analysis of contribution of patient factors to efficacy at week 12

\begin{tabular}{|c|c|c|c|c|}
\hline \multirow[t]{2}{*}{ Characteristic } & \multicolumn{2}{|c|}{ North American subgroup } & \multicolumn{2}{|c|}{ Non-North American subgroup } \\
\hline & $\overline{\text { Odds ratio }(95 \% \mathrm{CI})}$ & $P$ value & Odds ratio $(95 \% \mathrm{CI})$ & $P$ value \\
\hline \multicolumn{5}{|l|}{ Age } \\
\hline IGA $0 / 1$ & $0.98(0.96-1.00)$ & 0.0477 & $0.99(0.98-1.00)$ & 0.0586 \\
\hline IGA 0 & $0.99(0.97-1.01)$ & 0.4383 & $0.99(0.98-1.01)$ & 0.4438 \\
\hline PASI 75 & $0.98(0.96-1.00)$ & 0.0691 & $0.99(0.98-1.01)$ & 0.2899 \\
\hline PASI 90 & $0.98(0.97-1.00)$ & 0.0697 & $0.99(0.98-1.00)$ & 0.0749 \\
\hline PASI 100 & $0.99(0.97-1.01)$ & 0.1932 & $0.99(0.98-1.01)$ & 0.2697 \\
\hline \multicolumn{5}{|l|}{ Female sex } \\
\hline IGA $0 / 1$ & $1.25(0.70-2.25)$ & 0.4460 & $1.59(1.10-2.29)$ & 0.0130 \\
\hline IGA 0 & $1.52(0.83-2.77)$ & 0.1721 & $1.38(0.93-2.04)$ & 0.1076 \\
\hline PASI 75 & $1.20(0.64-2.25)$ & 0.5753 & $1.28(0.83-1.98)$ & 0.2657 \\
\hline PASI 90 & $1.99(1.12-3.56)$ & 0.0195 & $1.37(0.96-1.93)$ & 0.0788 \\
\hline PASI 100 & $1.35(0.74-2.46)$ & 0.3289 & $1.36(0.91-2.04)$ & 0.1351 \\
\hline \multicolumn{5}{|l|}{$\mathrm{BMI}$} \\
\hline IGA $0 / 1$ & $0.89(0.85-0.94)$ & $<0.0001$ & $0.93(0.90-0.97)$ & 0.0006 \\
\hline IGA 0 & $0.89(0.84-0.95)$ & 0.0002 & $0.90(0.85-0.94)$ & $<0.0001$ \\
\hline
\end{tabular}


Table 4 continued

\begin{tabular}{|c|c|c|c|c|}
\hline \multirow[t]{2}{*}{$\overline{\text { Characteristic }}$} & \multicolumn{2}{|c|}{ North American subgroup } & \multicolumn{2}{|c|}{ Non-North American subgroup } \\
\hline & Odds ratio $(95 \% \mathrm{CI})$ & $P$ value & Odds ratio $(95 \% \mathrm{CI})$ & $P$ value \\
\hline PASI 75 & $0.95(0.91-0.99)$ & 0.0099 & $0.95(0.91-1.00)$ & 0.0330 \\
\hline PASI 90 & $0.89(0.84-0.94)$ & $<0.0001$ & $0.93(0.90-0.97)$ & 0.0006 \\
\hline PASI 100 & $0.92(0.86-0.97)$ & 0.0035 & $0.90(0.86-0.95)$ & $<0.0001$ \\
\hline \multicolumn{5}{|l|}{ Baseline PASI } \\
\hline IGA $0 / 1$ & $0.97(0.94-1.01)$ & 0.1159 & $0.98(0.97-1.00)$ & 0.0194 \\
\hline IGA 0 & $1.00(0.96-1.04)$ & 0.9399 & $1.00(0.98-1.01)$ & 0.6833 \\
\hline PASI 75 & $0.99(0.96-1.02)$ & 0.3660 & $1.00(0.98-1.02)$ & 0.8913 \\
\hline PASI 90 & $1.01(0.98-1.04)$ & 0.6244 & $1.00(0.98-1.01)$ & 0.9451 \\
\hline PASI 100 & $0.99(0.95-1.03)$ & 0.7287 & $0.99(0.97-1.01)$ & 0.1910 \\
\hline \multicolumn{5}{|l|}{ Current smoker } \\
\hline IGA $0 / 1$ & $0.81(0.47-1.38)$ & 0.4367 & $0.74(0.53-1.03)$ & 0.0755 \\
\hline IGA 0 & $1.07(0.60-1.90)$ & 0.8183 & $0.78(0.53-1.15)$ & 0.2152 \\
\hline PASI 75 & $0.85(0.48-1.52)$ & 0.5912 & $0.84(0.56-1.24)$ & 0.3748 \\
\hline PASI 90 & $1.08(0.64-1.82)$ & 0.7861 & $0.76(0.55-1.06)$ & 0.1037 \\
\hline PASI 100 & $1.10(0.62-1.94)$ & 0.7499 & $0.85(0.57-1.27)$ & 0.4351 \\
\hline \multicolumn{5}{|l|}{ Caucasian } \\
\hline IGA $0 / 1$ & $0.49(0.23-1.04)$ & 0.0628 & $1.44(1.02-2.04)$ & 0.0371 \\
\hline IGA 0 & $0.73(0.36-1.50)$ & 0.3965 & $1.30(0.87-1.93)$ & 0.1964 \\
\hline PASI 75 & $0.69(0.31-1.55)$ & 0.3703 & $1.48(0.98-2.23)$ & 0.0634 \\
\hline PASI 90 & $0.79(0.40-1.58)$ & 0.5091 & $1.11(0.79-1.55)$ & 0.5473 \\
\hline PASI 100 & $0.83(0.40-1.70)$ & 0.6081 & $1.11(0.74-1.68)$ & 0.6088 \\
\hline
\end{tabular}

$B M I$ body mass index, $C I$ confidence interval, IGA Investigator's Global Assessment, NA North American, PASI Psoriasis Area and Severity Index

Odds ratio, 95\% confidence interval, and $P$ value were derived from a logistic regression model with study site, weight $(<90$ or $\geq 90 \mathrm{~kg}$ ), age, gender, BMI, baseline PASI score, race (Caucasian or non-Caucasian), current smoking status, and treatment as explanatory variables

populations. Although both NA and non-NA populations were predominately White, the NA population had a greater number of White patients and fewer Asian patients compared with the non-NA population. The non-NA population had more severe disease as indicated by greater PASI and IGA mod 2011 scores and BSA affected at baseline. It is important to note that these variations could obscure differences in responses between NA and non-NA patients.

In both the NA and non-NA populations, improvements in disease clearance were observed at week 1 and 50\% reduction in mean PASI score was achieved after 2.9 weeks of treatment with secukinumab $300 \mathrm{mg}$ and 3.7 weeks of treatment with secukinumab 
Table 5 Patient factors associated with secukinumab response at week 12

\begin{tabular}{|c|c|c|}
\hline Response criterion & Odds ratio $(95 \% \mathrm{CI})$ & $P$ value \\
\hline \multicolumn{3}{|l|}{ IGA $0 / 1$} \\
\hline Age & $0.99(0.98-1.00)$ & 0.0275 \\
\hline Female & $1.45(1.09-1.94)$ & 0.0114 \\
\hline BMI & $0.93(0.91-0.95)$ & $<0.0001$ \\
\hline Baseline PASI & $0.98(0.96-0.99)$ & 0.0012 \\
\hline North American & $1.24(0.90-1.73)$ & 0.1920 \\
\hline \multicolumn{3}{|l|}{ IGA 0} \\
\hline Female & $1.51(1.14-2.01)$ & 0.0042 \\
\hline $\mathrm{BMI}$ & $0.90(0.88-0.93)$ & $<0.0001$ \\
\hline North American & $1.84(1.32-2.56)$ & 0.0003 \\
\hline \multicolumn{3}{|l|}{ PASI 75} \\
\hline $\mathrm{BMI}$ & $0.94(0.92-0.96)$ & $<0.0001$ \\
\hline North American & $1.02(0.72-1.44)$ & 0.9328 \\
\hline \multicolumn{3}{|l|}{ PASI 90} \\
\hline Age & $0.99(0.98-1.00)$ & 0.0276 \\
\hline Female & $1.53(1.16-2.03)$ & 0.0028 \\
\hline BMI & $0.92(0.90-0.94)$ & $<0.0001$ \\
\hline North American & $1.24(0.90-1.69)$ & 0.1835 \\
\hline \multicolumn{3}{|l|}{ PASI 100} \\
\hline Age & $0.99(0.98-1.00)$ & 0.1167 \\
\hline Female & $1.39(1.01-1.91)$ & 0.0403 \\
\hline BMI & $0.91(0.89-0.94)$ & $<0.0001$ \\
\hline North American & $1.91(1.33-2.73)$ & 0.0004 \\
\hline
\end{tabular}

Factors predictive of secukinumab efficacy were determined by separate regression analyses including one of the following: current smoking status, race (Caucasian or non-Caucasian), gender, baseline BMI, and age in addition to NA and treatment as regressors (not shown)

$B M I$ body mass index, $C I$ confidence interval, $I G A$ Investigator's Global Assessment, $N A$ North American, $P A S I$ Psoriasis Area and Severity Index

Multiple regression analysis was then performed for factors with $P<0.05$ on separate analyses, all included together with study site, NA, and treatment as additional explanatory variables. Odds ratio, 95\% confidence interval, and $P$ value were derived from the multiple regression analysis

$150 \mathrm{mg}$. The response to secukinumab peaked at week 16 and was maintained to week 52 . Interestingly, non-NA patients receiving secukinumab $150 \mathrm{mg}$ tended to achieve greater efficacy responses than NA patients receiving this dose. These differences were most pronounced with PASI 75 and PASI 90 assessments, and separation began at approximately week 12 . The trend of lower responses between NA and non-NA patients with secukinumab $150 \mathrm{mg}$ was 


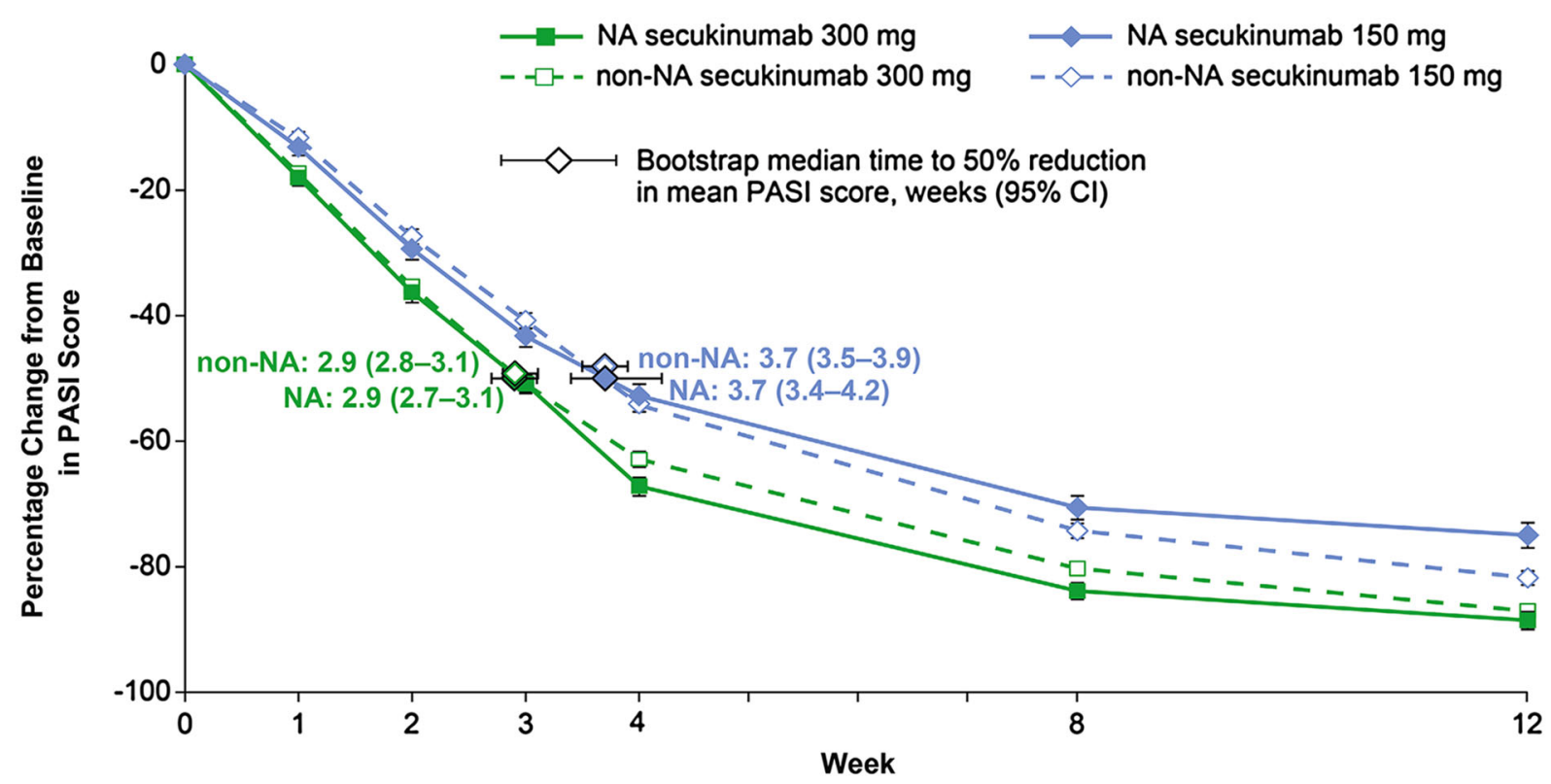

Fig. 7 Mean percent change in PASI score over time. A repeated-measures, mixed-effects model was used to analyze the mean percent change from baseline in PASI score. The median time to $50 \%$ reduction in mean PASI score was estimated from parametric bootstrap samples with use of linear interpolation between time points. $C I$ confidence interval, $N A$ North American, PASI Psoriasis Area Severity Index

Table 6 DLQI mean score and response at week 12 and week 52

\begin{tabular}{|c|c|c|c|c|}
\hline \multirow[t]{2}{*}{ DLQI parameter } & \multicolumn{2}{|c|}{ North American subgroup } & \multicolumn{2}{|c|}{ Non-North American subgroup } \\
\hline & $\begin{array}{l}\text { Secukinumab } \\
300 \mathrm{mg}\end{array}$ & $\begin{array}{l}\text { Secukinumab } \\
150 \mathrm{mg}\end{array}$ & $\begin{array}{l}\text { Secukinumab } \\
300 \mathrm{mg}\end{array}$ & $\begin{array}{l}\text { Secukinumab } \\
150 \mathrm{mg}\end{array}$ \\
\hline \multicolumn{5}{|l|}{ DLQI, mean score } \\
\hline Baseline & $15.2^{\mathrm{a}}$ & 14.2 & 12.8 & 12.7 \\
\hline Week 12 (absolute change) & $2.4(-12.7)$ & $4.1(-10.1)$ & $2.7(-10.1)$ & $3.2(-9.5)$ \\
\hline Week 52 (absolute change) & $2.8(-12.3)$ & $4.9(-9.3)$ & $2.4(-10.4)$ & $3.5(-9.2)$ \\
\hline \multicolumn{5}{|l|}{ DLQI $0 / 1$ response, $n / N(\%)$} \\
\hline Week 12 & $119 / 196(60.7)$ & $86 / 189(45.5)$ & $280 / 482(58.1)$ & $256 / 494(51.8)$ \\
\hline Week 52 & $128 / 198(64.6)$ & $84 / 190(44.2)$ & $335 / 484(69.2)$ & $283 / 494(57.3)$ \\
\hline
\end{tabular}

For mean DLQI scores, only patients with a value at both baseline and the respective postbaseline visit are included for each postbaseline visit value

DLQI Dermatology Life Quality Index

a Due to a difference in the number of patients with DLQI values at week 12 and week 52, the mean baseline score is shown for patients with values at week 12. The baseline score for North American patients receiving secukinumab $300 \mathrm{mg}$ with values at week 52 was 15.1

not observed with secukinumab $300 \mathrm{mg}$. This finding suggests that the therapeutic benefit of secukinumab is not being maximized with the 150-mg dose. The greater response to secukinumab $150 \mathrm{mg}$ in non-NA patients may be due to their lower body weight and/or greater 
NA Secukinumab $300 \mathrm{mg}$

Non-NA Secukinumab $300 \mathrm{mg}$
NA Secukinumab $150 \mathrm{mg}$

Non-NA Secukinumab $150 \mathrm{mg}$

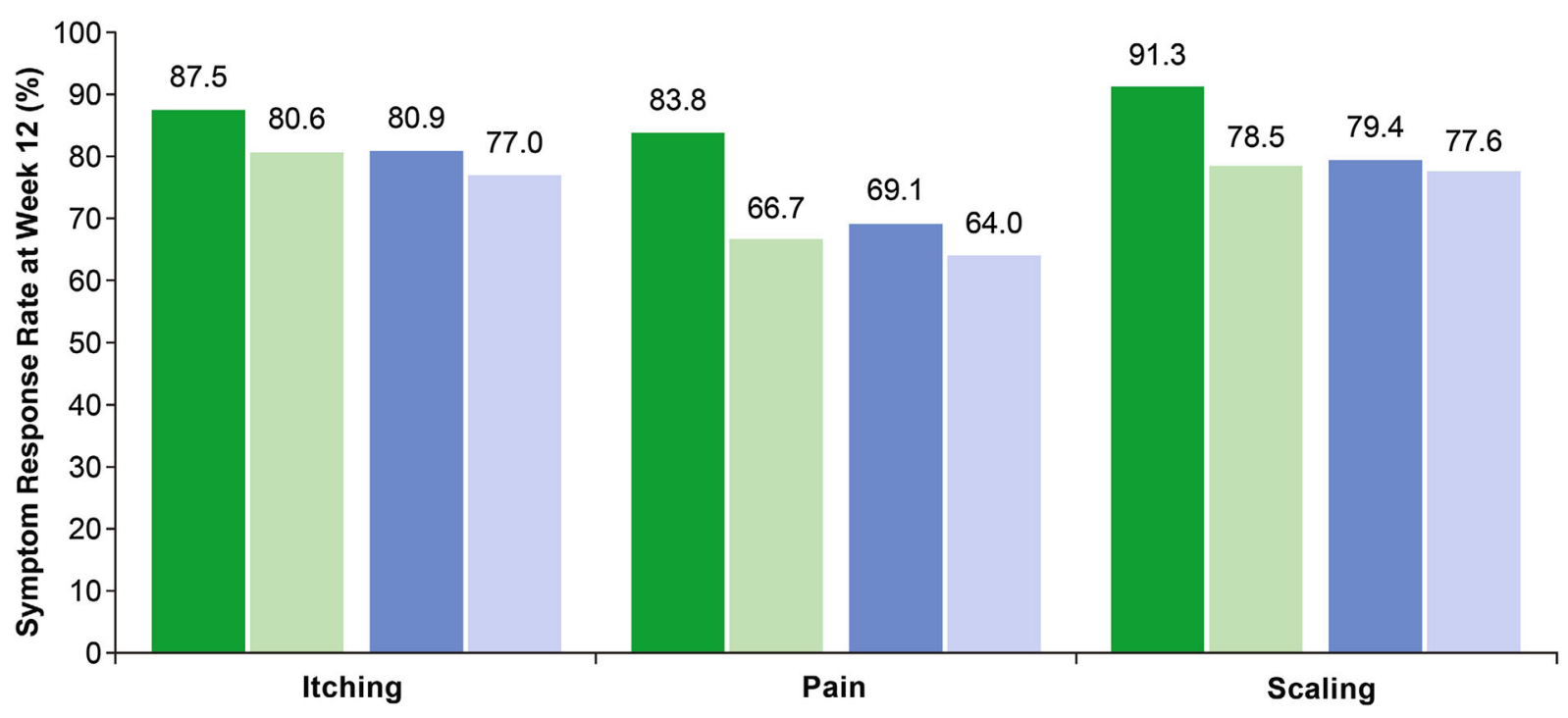

Fig. 8 Improvement in patient-reported symptoms of itching, pain, and scaling at week 12. The Psoriasis Symptom Diary was conducted only in ERASURE and FIXTURE. Improvement in symptoms was defined as a

disease severity at baseline. Responses to secukinumab $300 \mathrm{mg}$ were more consistent between NA and non-NA patients to week 52 . Overall, secukinumab $300 \mathrm{mg}$ provided greater and more rapid efficacy than secukinumab $150 \mathrm{mg}$ for both populations. At week 12, a trend toward greater response in NA patients was observed when adjusted for study site, body weight, treatment group, previous systemic treatment (including oral and biologic), previous biologic treatment, and baseline PASI score $(\leq 20$ or $>20)$. BMI had a significant effect on efficacy at week 12 in both NA and non-NA patients and was a predictor of lower efficacy in the overall patient population at week 12 . However, these findings might not be surprising, as it has been reported that higher weight can decrease the efficacy of biologics in patients with psoriasis [23]. NA geographical residence was a predictor of achieving total psoriasis clearance at week 12, but evaluation of efficacy responses over time showed that NA and nonNA patients had smaller differences in response prespecified point improvement at week 12 of 2.2, 2.2, and 2.3 for symptoms of psoriasis-related itching, psoriasisrelated pain, and psoriasis-related scaling, respectively. $N A$ North American

at later time points, especially for secukinumab $300 \mathrm{mg}$.

Improvements in baseline DLQI score at week 12 in both NA and non-NA patients were sufficient to meet the threshold (total DLQI score change $\geq 5$ ) required for a minimal clinically important difference in patients with psoriasis receiving biologic therapy [24]. These findings, and patient-reported improvements in symptoms of itching, pain, and scaling, indicate that secukinumab improved the quality of life of both NA and non-NA patients.

The safety profile of secukinumab was similar in both the NA and non-NA populations. Nasopharyngitis and upper respiratory tract infection were the two most common adverse events, with nasopharyngitis being more common in the non-NA population and upper respiratory tract infection being more common in the NA population. No specific safety observations were made based on geographic region.

Limitations of this study include that it was a post hoc analysis. 
Table 7 Adverse events in the North American and non-North American subgroups

\begin{tabular}{|c|c|c|c|c|}
\hline \multirow{2}{*}{$\begin{array}{l}\text { Variable, } n \text { (no. of cases per } 100 \\
\text { patient-years) }\end{array}$} & \multicolumn{2}{|c|}{ North American subgroup } & \multicolumn{2}{|c|}{ Non-North American subgroup } \\
\hline & $\begin{array}{l}\text { Secukinumab } \\
300 \mathrm{mg} \\
(n=202)\end{array}$ & $\begin{array}{l}\text { Secukinumab } \\
150 \mathrm{mg} \\
(n=191)\end{array}$ & $\begin{array}{l}\text { Secukinumab } \\
300 \mathrm{mg} \\
(n=488)\end{array}$ & $\begin{array}{l}\text { Secukinumab } \\
150 \mathrm{mg} \\
(n=501)\end{array}$ \\
\hline Serious adverse event & $17(9.6)$ & $11(6.6)$ & $31(6.9)$ & $37(8.2)$ \\
\hline Any adverse event & $166(242.2)$ & $153(263.9)$ & $409(275.2)$ & $409(271.5)$ \\
\hline $\begin{array}{l}\text { Discontinuation due to adverse event, } \\
n(\%)^{\mathrm{a}}\end{array}$ & $9(4.5)$ & $10(5.2)$ & $12(2.5)$ & $15(3.0)$ \\
\hline \multicolumn{5}{|l|}{ Most common adverse events } \\
\hline Nasopharyngitis & $37(22.7)$ & $36(24.3)$ & $135(35.5)$ & $128(33.1)$ \\
\hline Upper respiratory tract infection & $27(15.9)$ & $36(23.9)$ & $26(5.8)$ & $28(6.2)$ \\
\hline Headache & $17(9.7)$ & $14(8.8)$ & $62(14.8)$ & $51(11.8)$ \\
\hline Diarrhea & $7(3.9)$ & $6(3.6)$ & $47(10.9)$ & $39(8.8)$ \\
\hline Cough & $8(4.4)$ & $5(3.0)$ & $37(8.3)$ & $16(3.5)$ \\
\hline Pruritus & $1(0.5)$ & $1(0.6)$ & $32(7.3)$ & $32(7.2)$ \\
\hline Hypertension & $11(6.1)$ & $5(3.0)$ & $24(5.3)$ & $32(7.2)$ \\
\hline Arthralgia & $6(3.3)$ & $8(4.9)$ & $28(6.2)$ & $30(6.6)$ \\
\hline Back pain & $8(4.5)$ & $4(2.4)$ & $29(6.5)$ & $26(5.8)$ \\
\hline Muscle strain & $10(5.6)$ & $10(6.1)$ & $2(0.4)$ & $6(1.3)$ \\
\hline Oropharyngeal pain & $8(4.5)$ & $6(3.6)$ & $26(5.8)$ & $26(5.8)$ \\
\hline Bronchitis & $10(5.6)$ & $5(3.0)$ & $21(4.6)$ & $15(3.3)$ \\
\hline Nausea & $7(3.9)$ & $9(5.5)$ & $11(2.4)$ & $9(1.9)$ \\
\hline
\end{tabular}

Adverse events that occurred at a rate of at least five cases per 100 patient-years in either secukinumab group were included

a Exposure-adjusted incidence rates were not calculated for discontinuation due to adverse event

\section{CONCLUSIONS}

This study of pooled results from four phase 3 trials demonstrates that treatment with secukinumab for moderate to severe psoriasis provides high efficacy, regardless of geographic regions, and a similar safety profile across geographic regions.

\section{ACKNOWLEDGEMENTS}

Funding. This research was sponsored and funded by Novartis Pharma AG. Article processing charges were funded by Novartis Pharma AG. All authors had full access to all of the data in this study and take complete responsibility for the integrity of the data and accuracy of the data analysis.

Authorship. All named authors meet the International Committee of Medical Journal Editors (ICMJE) criteria for authorship for this manuscript, take responsibility for the integrity of the work as a whole, and have given final approval to the version to be published.

Medical Writing, Editorial, and Other Assistance. Technical assistance with editing 
and styling of the manuscript for submission was provided by Scott Forbes, PhD of Oxford PharmaGenesis Inc. The authors are fully responsible for all content and editorial decisions related to the development of this manuscript.

Prior Presentation. Results were previously presented, in part, at: The American Academy of Dermatology; March 20-24, 2015; San Francisco, CA, USA.

Disclosures. D. Pariser has served as a consultant and received honoraria from Abbott, Amgen, Astellas, Bickel Biotechnology, Celgene, Dermira, DUSA, LEO, MelaSciences, Novartis, Proctor \& Gamble, and Valeant. He has also participated in Advisory Boards and received honoraria from Galderma, Genentech, JanssenOrtho, Medicis, Ortho Dermatologics, Pfizer, and Stiefel. Dr. Pariser also served as an investigator and received research grants from Abbott, Amgen, Astellas, Asubio, Basliea, Celgene, Dow Pharmaceutical Sciences, Eli Lilly, Galderma, Graceway, Intendis, Johnson \& Johnson, LEO, Novartis, Novo Nordisk, Ortho Dermatologics, Peplin, Pfizer, Photocure ASA, Stiefel, and Valeant. E. Frankel has served as an investigator for Novartis, Amgen, Marujo, AbbVie, and Eli Lilly. She has also participated in Advisory Boards for Valeant, Anacor, and Allergan. J. Schlessinger: Allergan Pharmaceuticals, Alphaeon Corporation, Valeant Pharmaceuticals, Galderma, Novartis Pharmaceuticals, Johnson \& Johnson, AbbVie Pharma, Amgen, Bayer, Celgene, Dermira, Eli Lilly, Genentech, Merck, Merz, Pfizer, Boehringer Ingelheim, Revance, Tolmar, and Viamet Pharma. Y. Poulin: Advisory boards for AbbVie, Amgen, Celgene, Eli Lilly, and Janssen. Grants/research support from AbbVie, Amgen, Baxter, Boehringer Ingelheim, Bristol Myers Squibb, Celgene, Centocor/Janssen, Eli Lilly, EMD Serono, Isotechnika, Galderma, LeoPharma, Merck, Novartis, Pfizer, and Takeda. Speaker's bureau for AbbVie, Amgen, Celgene, GSK-Stiefel, and Janssen. R. Vender: Grants/research support from AbbVie, Amgen, Centocor, Dermira, Galderma, GSK, Leo, Eli Lilly, Takeda, Novartis, Merck, Pfizer, and Regeneron. Speakers' bureau/ honoraria from AbbVie, Amgen, Janssen, Galderma, GSK, Leo, Eli Lilly, Novartis, Pfizer,
Valeant, Actelion, Celgene, Cipher, and Palladin. Consulting fees from AbbVie, Amgen, Janssen, Galderma, GSK, Leo, Eli Lilly, Novartis, Pfizer, Valeant, Actelion, Celgene, Cipher, and Palladin. R. G. Langley has served on the scientific advisory board, as a principal investigator, or speaker for AbbVie, Amgen, Boehringer-Ingelheim, Celgene Corporation, Centocor Ortho Biotech, Eli Lilly, Novartis, and Pfizer. X. Meng is an employee of Novartis Pharmaceuticals Corporation. A. Guana is an employee of Novartis Pharmaceuticals Corporation. J. Nyirady is a former employee of Novartis Pharmaceuticals Corporation.

Compliance with Ethics Guidelines. The article does not contain any new studies with human or animal subjects performed by any of the authors.

Data Availability. The datasets generated during and/or analyzed during the current study are available from the corresponding author on reasonable request.

Open Access. This article is distributed under the terms of the Creative Commons Attribution-NonCommercial 4.0 International License (http://creativecommons.org/licenses/ by-nc/4.0/), which permits any noncommercial use, distribution, and reproduction in any medium, provided you give appropriate credit to the original author(s) and the source, provide a link to the Creative Commons license, and indicate if changes were made.

Author contributions All named authors meet the International Committee of Medical Journal Editors (ICMJE) criteria for authorship for this manuscript, take responsibility for the integrity of the work as a whole, and have given final approval to the version to be published.

\section{REFERENCES}

1. Shah SK, Arthur A, Yang YC, Stevens S, Alexis AF. A retrospective study to investigate racial and ethnic variations in the treatment of psoriasis with etanercept. J Drugs Dermatol. 2011;10:866-72. 
2. Alexis AF, Blackcloud P. Psoriasis in skin of color: epidemiology, genetics, clinical presentation, and treatment nuances. J Clin Aesthet Dermatol. 2014;7:16-24.

3. Ohtsuki M, Morita A, Abe M, Takahashi H, Seko N, Karpov A, et al. Secukinumab efficacy and safety in Japanese patients with moderate-to-severe plaque psoriasis: subanalysis from ERASURE, a randomized, placebo-controlled, phase 3 study. J Dermatol. 2014;41:1039-46.

4. Asahina A, Torii $\mathrm{H}$, Ohtsuki M, Tokimoto $\mathrm{T}$, Hase $\mathrm{H}$, Tsuchiya T, et al. Safety and efficacy of adalimumab treatment in Japanese patients with psoriasis: results of SALSA study. J Dermatol. 2016;43:1257-66.

5. Torii H, Terui T, Matsukawa M, Takesaki K, Ohtsuki M, Nakagawa $H$, et al. Safety profiles and efficacy of infliximab therapy in Japanese patients with plaque psoriasis with or without psoriatic arthritis, pustular psoriasis or psoriatic erythroderma: results from the prospective post-marketing surveillance. J Dermatol. $2016 ; 43: 767-78$.

6. Yusuf S, Wittes J. Interpreting geographic variations in results of randomized, controlled trials. N Engl J Med. 2016;375:2263-71.

7. Yasuda SU, Zhang L, Huang SM. The role of ethnicity in variability in response to drugs: focus on clinical pharmacology studies. Clin Pharmacol Ther. 2008;84:417-23.

8. Rachakonda TD, Schupp CW, Armstrong AW. Psoriasis prevalence among adults in the United States. J Am Acad Dermatol. 2014;70:512-6.

9. Brezinski EA, Dhillon JS, Armstrong AW. Economic burden of psoriasis in the United States: a systematic review. JAMA Dermatol. 2015;151:651-8.

10. Levy AR, Davie AM, Brazier NC, Jivraj F, Albrecht LE, Gratton D, et al. Economic burden of moderate to severe plaque psoriasis in Canada. Int J Dermatol. 2012;51:1432-40.

11. Vanderpuye-Orgle J, Zhao Y, Lu J, Shrestha A, Sexton A, Seabury S, et al. Evaluating the economic burden of psoriasis in the United States. J Am Acad Dermatol. 2015;72:961-7, e5.

12. Armstrong AW, Schupp C, Wu J, Bebo B. Quality of life and work productivity impairment among psoriasis patients: findings from the National Psoriasis Foundation survey data 2003-2011. PLoS One. 2012;7:e52935.

13. Armstrong AW, Robertson AD, Wu J, Schupp C, Lebwohl MG. Undertreatment, treatment trends, and treatment dissatisfaction among patients with psoriasis and psoriatic arthritis in the United States: findings from the National Psoriasis Foundation surveys, 2003-2011. JAMA Dermatol. 2013;149:1180-5.

14. Takeshita J, Duffin KC, Shin DB, Krueger GG, Robertson $\mathrm{AD}$, Troxel $\mathrm{AB}$, et al. Patient-reported outcomes for psoriasis patients with clear versus almost clear skin in the clinical setting. J Am Acad Dermatol. 2014;71:633-41.

15. Langley RG, Elewski BE, Lebwohl M, Reich K, Griffiths CE, Papp K, et al. Secukinumab in plaque psoriasis-results of two phase 3 trials. N Engl J Med. 2014;371:326-38.

16. Blauvelt A, Prinz JC, Gottlieb AB, Kingo K, Sofen $H$, Ruer-Mulard M, et al. Secukinumab administration by pre-filled syringe: efficacy, safety, and usability results from a randomized controlled trial in psoriasis (FEATURE). Br J Dermatol. 2015;172:484-93.

17. Paul C, Lacour JP, Tedremets L, Kreutzer K, Jazayeri S, Adams S, et al. Efficacy, safety and usability of secukinumab administration by autoinjector/pen in psoriasis: a randomized, controlled trial (JUNCTURE). J Eur Acad Dermatol Venereol. 2015;29:1082-90.

18. Thaçi D, Blauvelt A, Reich K, Tsai TF, Vanaclocha F, Kingo K, et al. Secukinumab is superior to ustekinumab in clearing skin of subjects with moderate to severe plaque psoriasis: CLEAR, a randomized controlled trial. J Am Acad Dermatol. 2015;73:400-9.

19. Langley RG, Feldman SR, Nyirady J, van de Kerkhof $P$, Papavassilis C. The 5-point Investigator's Global Assessment (IGA) Scale: a modified tool for evaluating plaque psoriasis severity in clinical trials. J Dermatolog Treat. 2015;26:23-31.

20. Finlay AY, Khan GK. Dermatology Life Quality Index (DLQI) - a simple practical measure for routine clinical use. Clin Exp Dermatol. 1994;19:210-6.

21. Lebwohl M, Swensen AR, Nyirady J, Kim E, Gwaltney CJ, Strober BE. The Psoriasis Symptom Diary: development and content validity of a novel patient-reported outcome instrument. Int J Dermatol. 2014;53:714-22.

22. Gottlieb AB, Blauvelt A, Prinz JC, Papanastasiou P, Pathan R, Nyirady J, et al. Secukinumab self-administration by prefilled syringe maintains reduction of plaque psoriasis severity over 52 weeks: results of the FEATURE trial. J Drugs Dermatol. 2016;15:1226-34.

23. Puig L. Obesity and psoriasis: body weight and body mass index influence the response to biological treatment. J Eur Acad Dermatol Venereol. 2011;25:1007-11.

24. Katugampola RP, Lewis VJ, Finlay AY. The Dermatology Life Quality Index: assessing the efficacy of biological therapies for psoriasis. Br J Dermatol. 2007; 156:945-50. 